\title{
Retraction Note: Role of the NF-KB signaling cascade and NF-KB-targeted genes in failing human hearts
}

\author{
Sudhiranjan Gupta ${ }^{1} \cdot$ Subha Sen ${ }^{1}$ \\ Published online: 27 March 2020 \\ (C) Springer-Verlag GmbH Germany, part of Springer Nature 2020
}

\section{Retraction Note: J Mol Med (2005) 83: 993-1004 https://doi.org/10.1007/s00109-005-0691-z}

The Editor-in-Chief has retracted this article [1] because a number of lanes in Figs. 3, 4 and 6 of this article are duplicated. Specifically:

- In Fig. 3 all three NF lanes appear to be the same, and the first $\mathrm{F}$ lane and the third, fourth and fifth $\mathrm{F}$ lanes appear to be the same.

- In Fig. 4a the first two NF lanes and fourth NF lane appear to be the same. The last two F lanes also appear to be the same.

- In Fig. $4 \mathrm{~b}$ there is similarity between the fourth NF lane and the third $\mathrm{F}$ lane. The first two $\mathrm{F}$ lanes and last $2 \mathrm{~F}$ lanes appear to be the same.

- In Fig. 4c all lanes for the control (GADPH) appear to be the same.

- In Fig. 6, for the the HMG-14 probe, the third and fourth NF lanes appear to be the same and the first four $\mathrm{F}$ lanes appear to be the same. The internal loading control GAPDH probe appears to be the same for all lanes.

The data are therefore unreliable. Both authors disagree with this retraction.

[1] S. Gupta and S. Sen, Role of the NF-kB signaling cascade and NF-kB-targeted genes in failing human hearts. J Mol. Med (2005) 83: 993-1004. https://doi.org/10.1007/s00109005-0691-z

The online version of the original article can be found at https://doi.org/ 10.1007/s00109-005-0691-z

Subha Sen

sens@ccf.org

1 Department of Molecular Cardiology, NB 50, Cleveland Clinic Foundation, 9500 Euclid Avenue, Cleveland, OH 44195, USA 